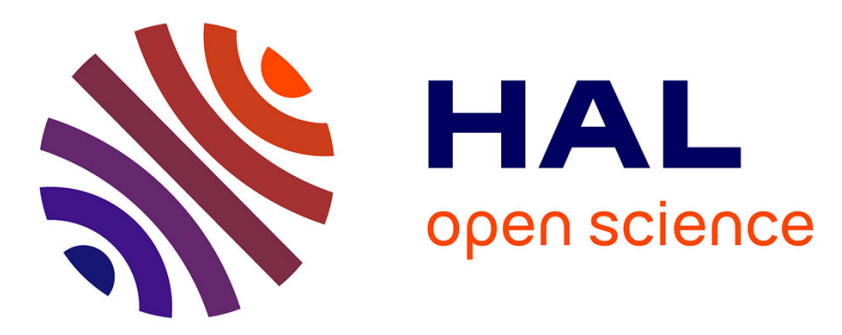

\title{
Is the Protected Designation of Origin (PDO) policy successful in sustaining rural employment?
}

\author{
Zohra Bouamra - Mechemache, Jad Chaaban
}

\section{To cite this version:}

Zohra Bouamra - Mechemache, Jad Chaaban. Is the Protected Designation of Origin (PDO) policy successful in sustaining rural employment?. International EAAE-SYAL. Spatia dynamics in agrifood systems: implications for sustainability and consumer welfare, European Association of Agricultural Economists (EAAE). INT., Oct 2010, Parma, Italy. 8 p. hal-02814729

\section{HAL Id: hal-02814729 \\ https://hal.inrae.fr/hal-02814729}

Submitted on 6 Jun 2020

HAL is a multi-disciplinary open access archive for the deposit and dissemination of scientific research documents, whether they are published or not. The documents may come from teaching and research institutions in France or abroad, or from public or private research centers.
L'archive ouverte pluridisciplinaire HAL, est destinée au dépôt et à la diffusion de documents scientifiques de niveau recherche, publiés ou non, émanant des établissements d'enseignement et de recherche français ou étrangers, des laboratoires publics ou privés. 


\title{
Is the Protected Designation of Origin (PDO) Policy Successful in Sustaining Rural Employment?
}

\author{
Bouamra-Mechemache Z. ${ }^{1}$, Chaaban J. ${ }^{2}$ \\ ${ }^{1}$ Toulouse School of Economics, INRA-GREMAQ, Toulouse, France \\ ${ }^{2}$ American University of Beirut, Faculty of Agricultural and Food Sciences, Beirut, Lebanon
}
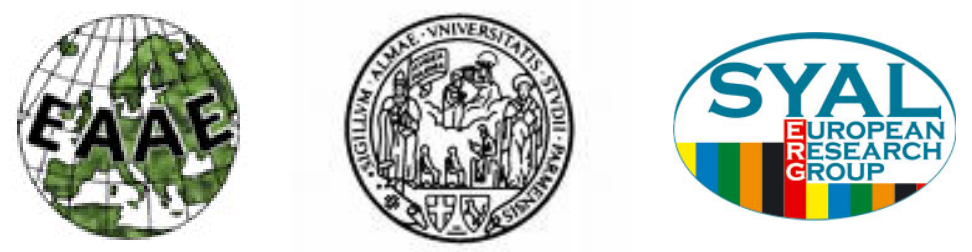

PAPER PREPARED FOR THE $116^{\mathrm{TH}}$ EAAE SEMINAR "Spatial Dynamics in Agri-food Systems: Implications for Sustainability and Consumer Welfare".

\author{
Parma (Italy) \\ October $27^{\text {th }}-30^{\text {th }}, 2010$
}

Copyright 2010 Bouamra-Mechemache Z. , Chaaban J. All rights reserved. Readers may make verbatim copies of this document for non-commercial purposes by any means, provided that this copyright notice appears on all such copies. 


\title{
Is the Protected Designation of Origin (PDO) Policy Successful in Sustaining Rural Employment?
}

\author{
Bouamra-Mechemache Z. ${ }^{1}$, Chaaban J. ${ }^{2}$ \\ ${ }^{1}$ Toulouse School of Economics, INRA-GREMAQ, Toulouse, France \\ ${ }^{2}$ American University of Beirut, Faculty of Agricultural and Food Sciences, Beirut, Lebanon
}

\begin{abstract}
This paper seeks to establish whether public agro-food interventions like food quality labels contribute or not to the promotion of rural employment. To this end, the paper uses original longitudinal firm and plant level datasets on the French cheese industry to assess the impact of the Protected Designation of Origin (PDO) label on rural employment. The data is used to test the impact of the PDO label on equilibrium market structure in the downstream cheese processing segment, and to establish backward linkages this segment has on upstream plant-level employment and the number of dairy farmers. Our results show that the PDO label has increased the equilibrium number of firms at the national level, because the introduction of this label has created market segmentation which reduced barriers to entry. In turn, this higher number of cheese firms resulted in more employment in dairy farms and processing plants at the district level. However, the PDO label exerts pressure on farmers to abide by strict production techniques, which may cause exit due to cost increases. Yet our estimates show that the employment benefits of this label outweigh the potential losses it might create due to its product specification stringency.
\end{abstract}

Keywords- Market Structure, Protected Designation of Origin, Rural Employment

\section{INTRODUCTION}

The Common Agricultural Policy (CAP) developed by the European Commission emphasized the role of food quality policy as a tool for product diversification and rural development. It has created different food quality labels, while reducing its direct price support instruments. These quality labels aimed at protecting the designations of agricultural and food products whose quality comes from their geographical origin. The main two labels are the Protected Designation of
Origin (PDO) and the Protected Geographical Indication (PGI) (European regulation 2081/92 followed by regulation 510/2006). Their main objectives are the development of rural activity to increase farmers' income; achieving a balance between supply and demand; developing less favored areas, and sustaining rural employment.

The literature on public quality labels has shown that they can be an efficient tool for producers to signal the quality of their products. When engaging in a PDO value chain, producers incur additional costs linked to the quality requirements (Bouamra-Mechemache and Chaaban, 2010a), but they benefit from a higher quality reputation and thus higher margins. Yet the profitability of the PDO label for producers ultimately depends on the market structure and the possibility of output control, as shown by Marette and Crespi (2003), Lence et al. (2007), and Hayes et al. (2004). This possibility of market control behavior arises even if the development of a welfare enhancing PDO label may occur in a perfect competition market as shown by Moschini et al. (2008), in the case where free entry is possible on the market.

While the literature on the effectiveness of the PDO label in raising agro-firms' income is abundant (c.f. review in Bouamra-Mechemache and Chaaban, 2010b); to our knowledge the literature which evaluates the impact of food quality labels on the rural economy at large is almost nonexistent. In fact, while the PDO policy applies to the final food product, the whole production chain (farmers and processors) is involved in its production. The competition and market structure downstream which affect the profitability of PDO firms will in turn impact the profitability of farmers upstream, in addition to the labeling and quality costs. This paper aims at 
addressing this issue, and contributes to the empirical evaluation of the PDO regulation as a tool for rural development.

It is devoted to the analysis of the ability of quality label to sustain the existence of agrofood chain by taking into account its incidence both on downstream firms and upstream farmers. It does not deal with the impact of PDO in the development of tourism in rural areas but rather focus on employment as a measure of rural activity and more particularly we analyze the contribution of PDO policy to develop employment in the agricultural and food sector and in particular in less favored areas.

The empirical analysis applies to the impact of the label "Appelation d'Origine Controlée" (AOC) on regional employment in the French cheese sector. The AOC label is older than its European equivalent PDO. France was one of the first country (with Italy) to introduce this kind of label. It applied first to wine in 1935 followed by the cheese sector. All French cheeses produced under AOC labels also benefits from the European PDO one. The French cheese sector is thus relevant to analyze the impact of PDO labels. It enables us to determine the regional effect of the AOC policy on the number of milk producers and on the number of dairy processors.

The empirical assessment of the AOC label requires data on the characteristics of both producers and products. Two databases at hand on the French dairy sectors provide this information. The first one (the Annual Firm Survey from SCESS) provides information on firms' characteristics while the second one (the Annual Dairy Survey) provides detailed data on production at the plant level and makes it possible in particular to distinguish PDO from non PDO production. In addition to this database, we use aggregate data to get information on the evolution of milk producers. We are then able to get information at the department level on a 10 year period (1996-2006). Our empirical analysis is based on the works of Sutton (1991) and Symeonidis (2002). We test the following empirical assumption by comparing PDO areas (at department level) to non PDO ones: the PDO label, by generating product differentiation relaxes the competition between PDO and non PDO firms. This would lead to have more firms on the market at the equilibrium. This higher number of cheese processors on the market could sustain the employment as well as the demand for milk.

An increase in the demand for PDO milk in a given area would lead to sustain the number of milk producers in this area. Our result shows that PDO label does have a positive effect on the number of milk farmers: a $10 \%$ increase in the share of PDO production in a given department would lead to a $8 \%$ increase in the number of cheese plants and to a $6 \%$ increase in the number of milk producers.

\section{INDUSTRY STRCTURE AND MARKET SIZE}

The majority of PDO registered products in the EU is composed of processed rather than raw food commodities, like cheese, wine, butter, and processed meat. For this, the development of a PDO label requires the participation of both upstream farmers and downstream processors. From a policy perspective, the impact of the PDO regulation on rural development will thus depend on the vertical relations between upstream producers and downstream processing firms. As a result, the outcome of the regulation will not only depend on the upstream market structure but also on the competitive structure of the downstream market. The structure of the downstream market will thus influence both the downstream and the upstream market. This will in turn determine the level of employment both in the downstream industry and in the input procurement market. Next we present one of the main theories that explains the determinants of market structure, and which applies quite well to food industries.

\section{A. Downstream market structure}

The determinant of market structure in a given industry can be sketched using the theory developed by Sutton (1991) and (1998) to analyze the effect of market size on the number of firms (the 'bounds approach'). This theory relies on game-theoretical models of strategic entry that can provide empirically testable and robust predictions concerning the determinants of market structure. These predictions depend on the type of industry. The first type 
corresponds to industries where firms produce homogenous or horizontally differentiated products with exogenous sunk cost. The second type refers to endogenous sunk cost industries. When sunk costs are exogenous, that is in industries which are characterized by low investments in $R \& D$ and advertising, Sutton shows that the number of firms in a free entry market is an increasing function of the size of the market relative to the sunk cost firms have to pay to enter the industry. The larger the market, the higher the number of firms and the higher the sunk costs, the lower the number of firms. The function specifying the lower bound to equilibrium concentration converges monotonically to zero as market size increase. For the second type of industries that are rather characterized by endogenous sunk costs - that is high level of R\&D and advertising investment - Sutton 's theory predicts, that even as the market grows without bounds, there is a strictly positive upper bound on the equilibrium number of firms.

Sutton's prediction for the two types of industry is illustrated in figure 1. In exogenous sunk cost markets, concentration declines towards zero, because, as market size increases, entrants find it profitable to build plants of efficient scale and enter the market. In contrast, in endogenous sunk cost markets, as market size increases, firms have to spend more on advertising and/or R\&D to maintain their market share, which leads to an escalation of (endogenous) spending that entrants are not able to handle. In figure 1 , entry is not possible in this type of markets beyond point $\mathrm{A}$, and concentration remains bounded away from zero.

Figure 1: Market size and concentration lower bounds

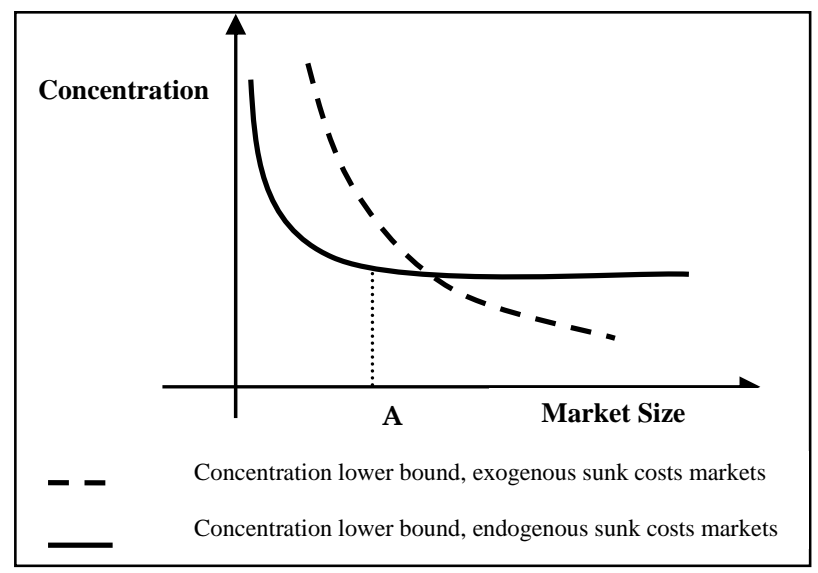

Empirical studies find evidence of Sutton's abovementioned predictions (Sutton (1991, Ch. 4, 5), Robinson and Chiang (1996), Lyons et al. (2001), Rogers (2001) and Giorgetti (2003). The market structure will be determined by market size, the level of production economies of scale, entry conditions and price competition. Below we detail some of the main predictions that we will test in this present paper.

\section{Market size}

The impact of market size (S) is straightforward from Sutton's theory. When market size increases, the number of firms in the industry will increase.

\section{P1: The number of firms on the downstream market increases with market size (S).}

\section{Economies of scale and entry condition}

The effective market size depends on the industry's minimum efficiency scale (MES). The higher the MES, the lower the number of firms in the industry (Sutton, 1991). It turns out that the number of downstream firms increases with the effective market size (S/MES).

The MES is also a proxy for technological barriers to entry. If it is high, then large sunk costs have to be incurred by a new firm that wants to enter the market, which ultimately makes its entry less likely. High MES may deter entry and tends to reduce the number of firms in the industry.

P2: The number of firms on the downstream market decreases with the level of the minimum efficient scale (S). 


\section{Price competition}

For exogenous sunk cost industries, Sutton (1991) has shown that any exogenous action that has a positive impact on prices will reduce the toughness of price competition and results in a larger number of firms. Namely, if price competition is softened due to the public PDO regulation, then introducing PDO labels should decrease concentration.

However, the effect of price competition in endogenous sunk cost industries depends on the relationship between endogenous sunk costs and price competition (Symeonidis [1997a, 1997b]). If price competition becomes more intense and advertising/R\&D expenditure increase (or remain constant), then the number of firms will decrease. However, if advertising/R\&D decreases, the number of firms may increase or decrease depending if the former decrease is sufficient to compensate for the decrease in prices. With PDO regulation, the resulting relaxation of competition may be followed by a reduction in advertising/R\&D competition, which makes entry more profitable. But it may also be the case that the PDO regulation may result in more advertising/R\&D expenditures from non PDO firms or for PDO firms that want to differentiate their products from other PDO labeled products. In this case, entry becomes less profitable and the number of firms on the market will not increase.

P3: If advertising/R\&D do not increase or do not increase by too much, we can predict that the PDO regulation will relax competition, thus increasing the number of firms in the industry.

\section{B. Vertical linkages}

The total number of farmers and plants will increase with the downstream market size, which in turn will depend on the sales to the downstream industry. The number of plants and farmers is directly linked to the number of firms in the market given the vertical structure of a given industry (figure 2).

Figure 2: Vertical structure of the industry and PDO feature.

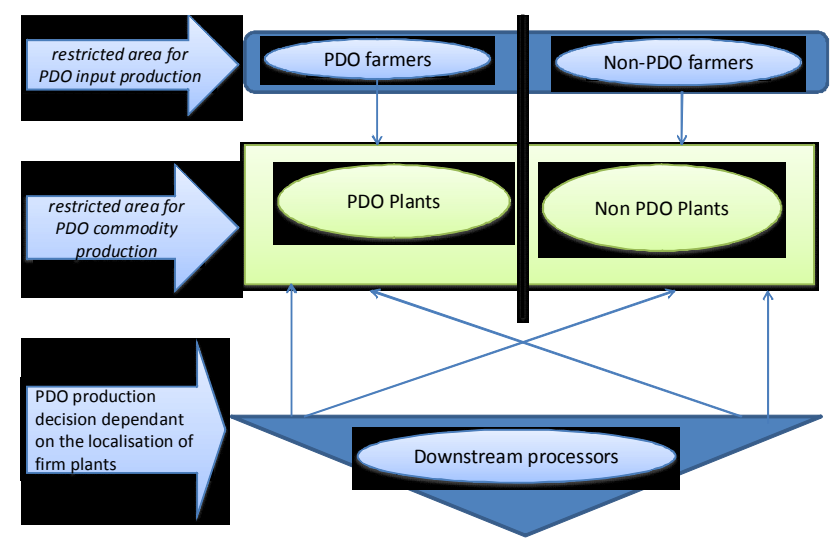

COMPETITION ON THE NATIONAL MARKET

P4: The total numbers of farmers and plants are increasing with the number of firms.

The agricultural market can be seen as a competitive exogenous sunk cost industry with a large number of farmers. First, the number of farmers in a given area will depend on the competitivity of farmers in this area. The relative competitivity of an area will depend on several factors. Among them, climate and geography will influence similarly all farmers in a given area and will also impact the productivity of farmers (production yields and farm size). Therefore the number of farmers has to be lower if the agro-food industry is located in an unfavoured area.

P5: The number of farmers is negatively linked with less favoured areas.

In addition, PDO production has a specific feature as both the input and the output productions have to be localized in the PDO region (cf. figure 2). It turns out that the downstream market features will impact differently the production areas, given the competitiveness of farms/plants in these areas as well as the possibility or not to produce PDO.

P6: The numbers of farmers in a given area are related to the PDO characteristics of this area.

Moreover, the procurement of raw inputs by a plant localized in a given area will depend on the nature of the transaction costs. If the transaction costs increases with distance, then plants have to be implemented in 
or near the procurement area. For instance, if inputs are perishable or if the transport costs of the input are high, then plants will be located in the neighbourhood of input production units.

P7: The numbers of farmers in a given area is increasing with the number of plants localised in the same area.

In the following section, we test the above predictions for the case of the cheese industry in France. In this industry, the milk produced upstream in the different geographical areas is processed by different plants. Because milk is a perishable product, plants have to be located in the same areas or in neighbouring ones. National firms may have several plants localised in the different areas, but they compete on the national market. The PDO label may influence milk production activity when adopted, as cheese companies have the option to produce either non PDO labelled products, or only PDO ones, or both. Their production decisions and the resulting downstream structure will influence the outcome on the activity in PDO producing areas.

\section{DATA AND EMPIRICAL MODEL}

\section{A. Data}

We use firm and plant surveys covering the period 1996-2006 provided by the French Administrative Direction of Statistics (INSEE). The first main dataset reports economic and administrative information at the firm level (EAE, Enquête Annuelle d'Entreprise) while the second set reports production activities and more detailed information on the industrial process at the plant level for dairy firms (EAL, Enquete Annuelle Laitièere), also provided by INSEE (Institut National de la Statistique et des Etudes Economiques). The EAE dataset is available only for firms with more than 20 employees, while the EAL set is exhaustive at the national French level. The proportion of AOC products in the total production of cheese amounts to around $17 \%$ over the period. We focus in this study on AOC cheese made from cow (30 AOC products) and sheep milk (3 AOC), which represent $97 \%$ of milk used in the processing of AOC cheese.
Each cheese processing firm is identified by an identifier at the country level (SIREN) and can thus be followed over the entire period using.

From EAL, we identify all plants using an identifier at the plant level (SIRET). This identification number is directly linked to firms' identifier, as the SIRET number is composed of the SIREN number of the firm plus two additional digits that uniquely identify each plant within the firm. We can therefore easily link each firm to its plants. Second, the EAL information at the plant unit makes possible to have precise information on the production of different types of cheeses. We have defined six categories of cheese products: hard cheese, semi hard cheese, soft cheese, blue cheese, processed cheese and other cheese. For each category, we observe the overall production as well as the proportion of PDO production. ${ }^{1}$

Around 90 firms are operational at the national level for each cheese category. From EAE, detailed information on the quantity of milk collected is available. For each plant, we recover the quantity collected as well as the number of farmers by milk production area (at the district level).

From this data, we compute our main dependent variables, which are also interrelated. At the country level, the number of firms per cheese category is denoted by $N F I R M S_{t, s}$ with $t$ is the subscript for year and $s$ the cheese sector category. At the district level $(d)$, the number of plants, plant workers and farmers is respectively denoted by $N P L A N T S_{d, t}, N E M P_{d, t}$ and $N F A R M E R S_{d, t}$. Summary statistics for these variables are shown in Table 1.

As discussed in the previous section, the main determinants of downstream market structure (i.e. the number of firms) are the market size, the advertising to sale ratio as well as the minimum efficient sale. These exogenous variables are computed for each observed year at the cheese sector level. The downstream market size (MSIZEi,t) is measured as the sum of cheese firms' turnover. The advertising to sale ratio $(A D V i, t)$ can be directly computed as overall advertising expenditures per sector divided by the

\footnotetext{
1. PDO can be directly observed for most of PDO cheese. For other PDO cheese, we recovered information at the plant level using other source of information. It was not possible to recover the information for goat cheese.
} 
sector's turnover. As shown it table 1, the French cheese industry could be classified as an endogenous sunk cost industry with a mean advertising-to-sales ratio equal to $6.2 \%$. The Minimum efficient scale per cheese category (MESi,t) is computed as the output of the median plant multiplied by the sector's assets. In addition, to evaluate the impact of the PDO regulation, a variable measuring the share of production under PDO label for each cheese category has been computed (S1_PDO).

Moreover, we use dummy variables to control for the district $k$ effect $\left(R E G_{k}\right)$. In order to incorporate upstream milk production characteristics, we use a variable measuring the share of PDO production in the district $\left(S 2 \_P D O_{k}\right)$ and dummies that identify districts localised in mountain areas (MOUNT) as well as in underprivileged areas (UNDER). We also incorporate in our analysis the effect of milk production externalities on the number of farmers in a given district, by computing the share of milk collected by plants which originates from the same district, as ratio of plants' overall collected milk input (S_MILK). If in a given district most plants collect milk from farmers located in the same district, then this will have an effect on the optimal number of farmers in this particular district in the long run.

Table 1: Summary statistics

\begin{tabular}{|l|c|c|c|c|}
\hline Variable & Mean & $\begin{array}{c}\text { Std. } \\
\text { Dev. }\end{array}$ & Min & Max \\
\hline NFIRMS & 4.50 & 0.52 & 2.71 & 5.61 \\
\hline NPLANTS & 2.72 & 1.04 & 0.00 & 5.59 \\
\hline NEMP & 4.81 & 1.55 & 0.00 & 7.88 \\
\hline NFARMERS & 6.76 & 1.16 & 2.71 & 9.08 \\
\hline MSIZE & 19.48 & 0.69 & 17.29 & 20.28 \\
\hline MES & 5.89 & 0.98 & 4.61 & 8.17 \\
\hline ADV & 6.15 & 4.78 & 0.05 & 26.01 \\
\hline S1_PDO & 0.09 & 0.06 & 0.00 & 0.37 \\
\hline S_MILK & 0.40 & 0.32 & 0.00 & 1.00 \\
\hline S2_PDO & 0.15 & 0.25 & 0.00 & 1.00 \\
\hline MOUNT & 0.19 & 0.39 & 0.00 & 1.00 \\
\hline UNDER & 0.28 & 0.45 & 0.00 & 1.00 \\
\hline MOUNTxS2_PDO & 0.05 & 0.15 & 0.00 & 0.72 \\
\hline UNDERxS2_PDO & 0.03 & 0.12 & 0.00 & 0.72 \\
\hline
\end{tabular}

\section{B. Empirical model}

We use a three-stage least square estimation system to simultaneously evaluate the determinants of the number of firms at the national level, as well as the number of plants, the number of cheese-processing units' employees, and the number of dairy farmers at the district level.

Equation (1) corresponds to the first market stage where the number of firms in a given cheese sector is estimated as a function of the sector's market size, the minimum efficient scale, the level of advertising and the share of PDO for the sector as well as an error term $\varepsilon_{\mathrm{i}, \mathrm{t}}$.

$\ln$ NFIRMS $_{\mathrm{i}, \mathrm{t}}=\beta_{0}+\beta_{1} \ln$ MSIZE $_{\mathrm{i}, \mathrm{t}}+\beta_{2} \ln \mathrm{MES}_{\mathrm{i}, \mathrm{t}}+\beta_{3} \mathrm{ADV}_{\mathrm{i}, \mathrm{t}}+\beta_{4} \mathrm{~S}_{1-} \mathrm{PDO}_{\mathrm{i}, \mathrm{t}}+\varepsilon_{\mathrm{i}, \mathrm{t}}$

Equation (2) establishes the direct link between the number of cheese processing plants and the corresponding number of firms at the district level.

$$
\text { ln NPLANTS }{ }_{\mathrm{d}, \mathrm{t}}=\delta_{0}+\delta_{1} \ln \mathrm{NFIRMS}_{\mathrm{d}, \mathrm{t}}+\sum_{\mathrm{k}} \delta_{\mathrm{k}} \mathrm{REG}_{\mathrm{k}}+\mu_{d, \mathrm{t}}(
$$

where NFIRMS $_{d, t}$ is the equivalent number of firms active in district $\mathrm{d}$ at time $\mathrm{t}$. The equation also controls for regional dummies through the REG dummies.

Equation (3) provides the direct linkage between the number of plants and the number of plant employees at the district level.

$\ln \mathrm{NEMP}_{\mathrm{d}, \mathrm{t}}=\alpha_{0}+\alpha_{1} \ln \mathrm{NPLANTS}_{\mathrm{d}, \mathrm{t}}+v_{\mathrm{d}, \mathrm{t}}$

Equation (4) establishes the determinants of the number of dairy farmers in a given district. This depends on the number of plants operational in the district, the share of milk from the district collected by these plants, in addition to district-specific dummy variables:

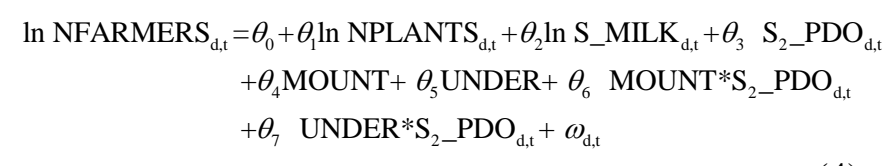


We estimate two systems of equations by applying Zellner's Seemingly Unrelated Regression (SUR) technique. We first jointly estimate (1), (2) and (3) to analyse the determinants of industry employment per district. We then focus on the number of farmers by estimating the system of equations (1), (2) and (4). Econometric estimations are conducted using Stata 10.

\section{RESULTS}

Table 2 details our first set of regression estimates. Our sector-level regression confirms our first and second predictions above (P1 and P2): The number of cheese processing firms on the downstream market increases with market size (S) and decreases with the level of the minimum efficiency efficient scale (S), as both parameters for MSIZE and MES are highly significant with the expected signs. Interestingly, our third prediction (P3) is also validated by our estimation results, as the number of firms seems to decrease with sector's advertising intensity, and to increase with the share of PDO production in the sector. A high PDO production in a given cheese sector seems to promote the number of firms operational on the market.

Table 2: Three-stage Least Squares estimation results, determinants of district-level employment in dairy processing plants

\begin{tabular}{|c|c|c|c|}
\hline & $\begin{array}{c}\text { NFIRMS } \\
\text { coef }\end{array}$ & $\begin{array}{c}\text { NPLANTS } \\
\text { coef }\end{array}$ & $\begin{array}{l}\text { NEMP } \\
\text { coef }\end{array}$ \\
\hline MSIZE & $0.384^{* * *}$ & & \\
\hline MES & $-0.234 * * *$ & & \\
\hline $\mathrm{ADV}$ & $-0.024 * * *$ & & \\
\hline S1_PDO & $3.237 * * *$ & & \\
\hline $\begin{array}{l}\text { NFIRMS } \\
\text { reg (dummies) }\end{array}$ & & $\begin{array}{l}0.405^{* * *} \\
\text { (omitted) }\end{array}$ & \\
\hline NPLANTS & & & $0.892^{* * *}$ \\
\hline _cons & $-1.678^{* *}$ & & $2.407 * * *$ \\
\hline R-sq & 0.44 & 0.91 & 0.29 \\
\hline
\end{tabular}

As for the other regressions, the number of firms coefficient has a positive and significant effect on the number of plants, and the number of plants in turn have a positive and significant effect on the number of plant employees (these are expected direct linkage effects).

Figure 3 details the effect of Minimum Efficient Scale (MEA) on market structure (the number of firms).

Figure 3: Number of firms in relation to Minimum Efficient Scale, by PDO intensity

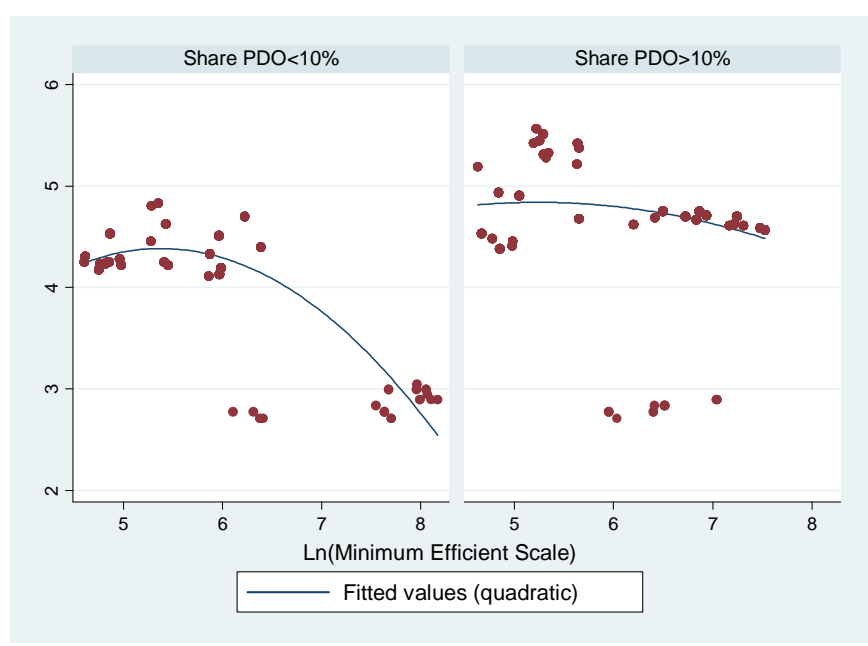

When the MES is low (which indicates low barriers to entry), the number of firms increases slightly, but when the MES becomes higher, technological entry barriers increase, resulting in a lower equilibrium number of firms. However, the impact of the MES follows a different pattern for non PDO and PDO intensive sectors. While the MES has a strong negative impact for non PDO firms, it marginally affects PDO firms, suggesting that PDO firms are less hurt by market barriers. PDO regulation relaxes competition by compressing the production scale necessary to be profitable under this label.

Table 3 provides estimates of the second set of equations, where we include now the number of farmers at the district level. Similar to the previous results, the regressors in the NFIRMS and NPLANTS equations are all significant with the expected signs. Also as expected, the greater number of plants in a 
district and the higher share of milk collected from within the district increases the number of dairy farmers. Interestingly, the higher the share of PDO production in the district (S2_PDO) reduces the number of farmers there, but not when crossed with districts that are in mountainous areas.

Table 3: Three-stage Least Squares estimation results, determinants of district-level numbers of dairy farmers

\begin{tabular}{|lccc|}
\hline & $\begin{array}{c}\text { NFIRMS } \\
\text { coef }\end{array}$ & $\begin{array}{c}\text { NPLANTS } \\
\text { coef }\end{array}$ & $\begin{array}{c}\text { NFARMERS } \\
\text { coef }\end{array}$ \\
\hline MSIZE & $0.395^{* * *}$ & & \\
MES & $-0.238^{* * *}$ & & \\
ADV & $-0.025^{* * *}$ & & \\
S1_PDO & $3.086^{* * *}$ & & \\
NFIRMS & & $0.531^{* * *}$ & \\
reg (dummies) & & (omitted) & \\
NPLANTS & & & $1.418^{* * *}$ \\
S_MILK & & & $0.609^{* *}$ \\
S2_PDO & & & $-0.905^{* *}$ \\
MOUNT & & & $-1.810^{* * *}$ \\
UNDER & & & $-1.613^{* * *}$ \\
MOUNTxS2_PDO & & & $1.652^{* *}$ \\
UNDERxS2_PDO & & & -0.144 \\
_cons & & & $12.656^{* * *}$ \\
R-sq & $-1.855^{* * *}$ & & 0.53 \\
\hline Note: $* * *$ p $<0.01, * *$ \\
Nb. Obs. 349
\end{tabular}

\section{CONCLUSION}

The empirical analysis has showed that the PDO label seems to positively contribute to the sustainability of rural employment, mainly through the downstream market channel. A higher share of PDO cheese products relaxes market competition, which enables more firms to operate on a larger market. In turn, the greater number of cheese processors implies more processing plants, typically implanted close to dairy farmers, which then translates into greater (or sustained) employment in these plants and higher numbers of dairy farmers.
Yet the PDO label seems to have a negative direct economic influence on the number of farmers at the district level. Our econometric results show that the number of farmers decreases the higher the share of PDO at the district level. This seems to indicate that the PDO label is imposing constraints on farmers by adopting stringent production techniques, which ultimately impacts their cost of production. This negative effect is however overtaken by the downstream market effect, where demand for milk by plants affiliated with cheese processors is expanding due to the impact the PDO label is exerting on the overall market structure downstream.

\section{REFERENCES}

1. Bouamra-Mechemache Z., Chaaban J. (2010a) Determinants of Adoption of Protected Designation of Origin Label: Evidence from the French Brie Cheese Industry", Journal of Agricultural Economics, 61(2): 225-239.

2. Bouamra-Mechemache, Zohra and Chaaban, Jad (2010b). Protected Designation of Origin Revisited. Journal of Agricultural \& Food Industrial Organization: Vol. 8 : Iss. 1, Article 5. Available at: http://www.bepress.com/jafio/vol8/iss1/art5

3. Hayes, D. J., Lence, S. H., and Stoppa, A. (2004). Farmer-owned brands. Agribusiness, 20(3):269 285.

4. Lence, S., Marette, S., Hayes, D., and Foster, W. (2007). Collective marketing arrangements for geographically differentiated agricultural products: Welfare impacts and policy implications. American Journal of Agricultural Economics, 89:947 - 963.

5. Marette, S. and Crespi, J. M. (2003). Can quality certification lead to stable cartels? Review of Industrial Organization, 23(1):43 - 64.

6. Moschini, G., Menapace, L., and Pick, D. (2008). Geographical indications and the competitive provision of quality in agricultural markets. American Journal of Agricultural Economics, 90(3):794 - 812.

7. Sutton, J. (1991). Sunk costs and market structure: Price competition, advertising, and the evolution of concentration. Cambridge, Mass. and London.

8. Symeonidis, G. (2002). The Effects of Competition: Cartel Policy and the Evolution of 
Strategy and Structure in British Industry, volume 1 of MIT Press Books. The MIT Press.

(Zohra.Bouamra@toulouse.inra.fr) 